\title{
Improvement of trochanteric bone quality in an osteoporosis model after short-term treatment with parathyroid hormone: a new mechanical test for trochanteric region of rat femur
}

\author{
M. Tezval • E. K. Stuermer • S. Sehmisch • T. Rack • \\ A. Stary • M. Stebener • F. Konietschke • \\ K. M. Stuermer
}

Received: 7 November 2008 / Accepted: 6 April 2009/Published online: 13 May 2009

(C) The Author(s) 2009. This article is published with open access at Springerlink.com

\author{
Abstract \\ Summary We have examined the changes induced in the \\ trochanteric region of femur of ovariectomized rat after \\ administration of estradiol and p.arathyroid hormone. We \\ have developed a reproducible biomechanical test and \\ M. Tezval $\cdot$ E. K. Stuermer $\cdot$ S. Sehmisch $\cdot$ T. Rack $\cdot$ A. Stary $\cdot$ \\ M. Stebener $\cdot$ K. M. Stuermer \\ Department of Trauma and Reconstructive Surgery, \\ Georg-August-University of Goettingen, \\ Goettingen, Germany \\ E. K. Stuermer \\ e-mail: e.stuermer@med.uni-goettingen.de \\ S. Sehmisch \\ e-mail: stephan.sehmisch@med.uni-goettingen.de \\ T. Rack \\ e-mail: track@gwdg.de \\ A. Stary \\ e-mail: annestary@gmx.de \\ M. Stebener \\ e-mail: mstebener@aol.com \\ K. M. Stuermer \\ e-mail: km.stuermer@med.uni-goettingen.de \\ F. Konietschke \\ Department of Medical Statistics, \\ Georg-August-University of Goettingen, \\ Goettingen, Germany \\ e-mail: fkoniet@gwdg.de \\ M. Tezval ( $\bowtie)$ \\ Department of Trauma and Reconstructive Surgery, \\ University Hospital, Goettingen, \\ Robert Koch St. No. 40, \\ 37075 Goettingen, Germany \\ e-mail: mtezval@med.uni-goettingen.de
}

produced trochanteric fractures to evaluate stiffness and strength of this region in addition to histomorphometry. Introduction We investigated the short-term effects of parathyroid hormone (PTH) and estrogen (E) on the strength of the rat trochanteric region in a new mechanical test.

Methods Forty-four 3-month-old female Sprague-Dawley rats were ovariectomized and 8 weeks later treated with soy-free diet (C), daily applications of orally supplied E $(0.5 \mathrm{mg} / \mathrm{kg}$ food) or subcutaneously injected PTH $(0.014 \mathrm{mg} / \mathrm{kg})$, for 5 weeks, and an additional untreated group was added as sham-operated. The femurs were examined for biomechanical and histomorphometric changes.

Results Our new mechanical test was validated in a right-left comparison. The PTH treatment induced significantly superior biomechanical results $\left(F_{\max }=225.3 \mathrm{~N}\right.$, stiffness $=314.9 \mathrm{~N} / \mathrm{mm})$ compared to $\mathrm{E}\left(F_{\max }=182.9 \mathrm{~N}\right.$, stiffness $=237.2 \mathrm{~N} / \mathrm{mm}), C\left(F_{\max }=166.03 \mathrm{~N}\right.$, stiffness $=$ $235.56 \mathrm{~N} / \mathrm{mm})$, and sham $\left(F_{\max }=192.1 \mathrm{~N}\right.$, stiffness $=$ 267.2 N/mm). Animals of the PTH group demonstrated a significantly improved trabecular bone structure and area (75.67\%) in comparison to the $\mathrm{E}(61.04 \%)$ and $\mathrm{C}(57.18 \%)$ groups.

Conclusion Our new biomechanical test is valid and produces trochanteric fracture. Our results show that the short-term antiosteoporotic effects of PTH are in the trochanteric region of ovariectomized rat superior to $\mathrm{E}$.

Keywords Biomechanical test · Estradiol .

Histomorphometric test - Osteoporosis .

Parathyroid hormone $\cdot$ Trochanteric region 


\section{Introduction}

Estrogen, the predominant female sex hormone, has commonly been considered the most important nonmechanical (endocrine) regulator of bone metabolism [1]. Estradiol esters and conjugated estrogens have strong suppressive effects on climacteric complaints, as they prevent or decelerate osteoporotic activities in the bone. However, long-term estrogen treatments are accompanied by the undesired side effects of increased risk of mammary cancer, strokes, and thrombo-embolism [2, 3].

In addition to serum calcium regulation and stimulation of bone resorption [4], parathyroid hormone (PTH) is known to stimulate bone formation under certain conditions [5]. It is also known that PTH can cause bone resorption and is thus associated with both anabolic and catabolic activities [6-10]. The possibility that PTH has paradoxical effects on bone was first proposed by Selye in 1932 after he observed that continuous infusion in vivo of crude preparations of PTH-elevated bone formation and also dominantly bone resorption, while intermittent administration of the hormone resulted mainly in a stimulation of bone formation especially at the trabecular surface. Later studies have emphasized the importance of evaluating the effects of PTH not only in the trabecular region but also in cortical areas.

The ovariectomized (OVX) rat serves as a validated experimental model of post-menopausal osteoporosis. Animals develop substantial osteoporosis within a few months after ovariectomy [11]. The proximal metaphysis of the tibia and lumbar vertebrae are suitable common sites used to investigate bone histomorphometric and mechanical changes in this rodent osteoporosis model. These regions, however, have a high content of trabecular bone, but a very thin cortical shell $[12,13]$. Next to the femoral neck fracture, the trochanteric fracture is one of the most common fracture types of the proximal femur in human, especially in patients with progressive osteoporosis. This part of the femur contains both trabecular and cortical bone, in contrast to the femoral shaft. The trochanteric part of femur therefore seems to be a further and additional important area to investigate the biomechanical changes induced after treatment with antiosteoporosis drugs such as parathyroid hormone, which appear to rapidly influence both cortical and trabecular bone formation. The known sufficient and thick muscle insertions (cuff) in this region make this skeletal site also interesting for evaluating the effect of mechanical stimulations like whole body vibrations (like high-frequency, low-magnitude mechanical stimulations).

To the best of our knowledge, there are no published studies that have used mechanical tests to characterize the trochanteric region of the femur to date, presumably because of the many problems encountered in designing a reproducible bending and breaking test in this location. The most conventional methods for evaluating rat hip failure are based on axial compression approaches [14]. However, as most osteoporotic hip fractures result from lateral falls, it is necessary to establish additional mechanical testing methods that more closely resemble clinical conditions (lateral loading). It is also necessary to study the effects of antiosteoporosis drugs in skeletal sites that exhibit both sizeable trabecular and cortical areas with an intact periost covering.

In this work, we used histomorphometric and biomechanical tests to study the changes in the trochanteric region of femur of ovariectomized rat after administration of $\mathrm{E}$ or PTH. To evaluate the biomechanical changes in rat trochanteric region after drug treatment, it was necessary first to produce a trochanteric fracture.

\section{Materials and methods}

Development of a new breaking test for the trochanteric region of the rat femur

A novel mechanical loading configuration was developed to measure the strength of the trochanteric region of the femur, according to the design of one of the authors (K.M. Stuermer). The left and right femurs of non-OVX rats were tested in a direction vertical to the greater trochanter. The femoral head was fixed in a $4 \mathrm{~mm}$ deepening at one end of the system, while the femoral shaft was horizontally positioned between two metallic movable rolling cylinders. The distal end of the femur was in contact with the aluminum plate without any rigidity. The lesser trochanter did not come into contact with the aluminum plate at all because of a groove made to allow for free movement. The angle between the femoral shaft and the horizontal line was nearly $0^{\circ}$. Force was applied vertically to the greater trochanter using a roller stamp (Fig. 1a-c).

The force was applied with a ZWICK-testing machine, type 145660 Z020/TND (Zwick/Roell, Ulm, Germany). The measurement range was from 2 to $400 \mathrm{~N}$, at a relative accuracy of $0.2 \%$ at $0.4 \%$ nominal force (FN). During the bending and breaking test, the femur was allowed to move longitudinally as it was dynamically fixed between the two roller clamps. The stamp was driven down to the greater trochanter until the bone was broken. Displacement and load were recorded, and ultimate strength (maximal load, $\mathrm{N}$ ), stiffness (slope of the linear part of the curve, representing elastic deformation, $\mathrm{N} / \mathrm{mm}$ ), and the yield load were calculated.

Fifteen pairs of right-left femurs of non-OVX rats were studied with this new breaking test before starting 

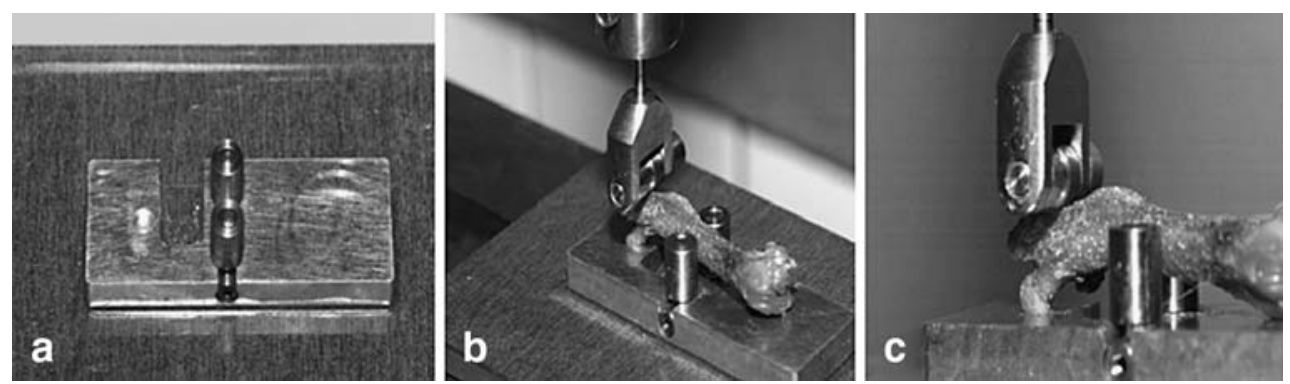

Fig. 1 a-c The new breaking test is designed to produce trochanteric fractures for studying of biomechanical strength of trochanteric region of rat femur (here femur of Sprague-Dawley rat). The femoral head was fixed in a 4-mm deepening on the other end of the system. The femoral shaft was horizontal between two metallic movable rolling cylinders. The distal end of the femur was in contact with the aluminum plate without any rigidity. The force was applied with a ZWICK-testing machine, type 145660 Z020/TND (Zwick/Roell, Ulm, Germany) the comparative bioassay. Each bone and its contralateral partner underwent the breaking test on the same day, and the test order of bones was random. All bones were analyzed by the same operator.

\section{Comparative bioassay}

\section{Experimental animals and substances}

The experiments were carried out using 44 3-month-old female Sprague-Dawley rats fed with a standard diet ad libitum. The animals were randomized by weight into four experimental groups $(n=11$ in each group): OVX soy-free group (C), PTH group receiving daily subcutaneous injections of $0.014 \mathrm{mg} / \mathrm{kg} 1,34$ parathyroid hormone, and the estrogen (E) group receiving $15 \mathrm{~g} /$ day food, so the average $E$ intake was $0.5 \mathrm{mg} E /$ day corresponding to $0.325 \mathrm{mg}$ free $17-\beta$-estradiol, and an untreated nonOVX group was added as sham-operated group. The experimental procedures were approved by the local ethics commission under German animal protection law (permission from 11.03.1998, AZ: 509.42502/01-02.98 Bezirkregierung Braunschweig). Eight weeks before starting the drug treatments, bilateral ovariectomy was performed. After 5 weeks of drug treatments, the rats were euthanized, and bilateral femurs were dissected free of soft tissue and then submitted to biomechanical and histomorphometric tests.

\section{Intravital fluorochrome labeling}

During the 35 days of drug treatment, animals were subcutaneously injected with four fluorescent agents (Merck, Darmstadt, Germany) to label the process of bone formation and restoration. The following fluorochromes were used: xylenol orange $(90 \mathrm{mg} / \mathrm{kg}$ ) on day 13 , calcein green $(10 \mathrm{mg} / \mathrm{kg})$ on day 18 , alizarin red $(30 \mathrm{mg} / \mathrm{kg})$ on day 24 , and tetracycline $(25 \mathrm{mg} / \mathrm{kg})$ on day 35. The results of the fluorochrome labeling were analyzed quantitatively in the cross sections of femurs $11 \mathrm{~mm}$ distal from femoral head in the subtrochanteric region. Evaluation of the changes and the localization of bone formation in the cortical surface was the aim of fluorochrome analysis.

\section{Biomechanical test}

During the breaking test, the actual strength was recorded every $0.1 \mathrm{~mm}$ during the lowering of the stamp. The testXpert software continuously recorded the force applied until total failure of the bone occurred. After the failure, the software program indicated the maximum load $\left(F_{\max }\right)$ and the breaking strength. The breaking strength is the last measured point of the running graph and has no explanatory power. In the right-left comparison and the comparative bioassay, $F_{\max }$ is the highest force that the femur can withstand.

According to the method described in Stuermer et al. (2006), increases in elastic deformation (stiffness = elasticity) were calculated, and the transition point of elastic to plastic deformation was determined from the digital data [15]. This point represents the yield load of the bone. To determine this point, we calculated a regression line and the standard deviation (SD) with the individual data of the linear part of the graph. We defined the transition point of elastic to plastic deformation as a decrease of stiffness of more than twice the SD.

\section{$X$-ray examination of fracture mode}

Radiographs in the anterior-posterior and lateral view of all femurs tested in the comparative bioassay were taken. A 
special film (Kodak SR type 45) and a Faxitron fine-focus cabinet X-ray system (model 43855A; Faxitron X-ray System) with $40 \mathrm{kV}$ were used.

\section{Bone histomorphometry and cancellous bone structure analysis}

The undecalcified femurs were dissected and carefully cleaned of clinging soft tissues, fixed in $70 \%$ ethanol for $48 \mathrm{~h}$, dehydrated through an alcohol gradient, and embedded in methyl methacrylate. Serial sagittal sections $(150 \mu \mathrm{m}$ thick) through the proximal femur were cut with a microtome (Leica, Sägemikrotom 1600). The region of interest for the histomorphometric test was a frame where the proximal part of femur included the head (without epiphysis), neck, and trochanteric region. The microradiographs of the sagittal sections were used to measure structural indices of both trabecular and cortical bone areas.

A digitizing morphometric system was used to measure bone histomorphometric parameters. The system consisted of a microscope (Leica-System MZ 7.5), a digitizing pad coupled to a PC, and a morphometry program (Qwin software).

The epiphysis line of the capitis femoris represented the proximal border of the histomorphometry frame. The distal limit of the sections was marked by the base of the major trochanter (Fig. 5a-d). We assessed ratio of trabecular bone area to total cancellous bone area at the prox. Femur (Tb. Ar) and trabecular connectivity $\left(\mathrm{N} . \mathrm{Nd} / \mathrm{mm}^{2}\right)$ and trabecular thickness (Tb.Wi).

It is known that minimal changes in cortical surface occur first a long time after OVX. The Ct.Wi between all of the rat groups shows often a large standard deviation within each group, and the real changes in this region remain difficult to measure. In our study, we measured the ratio between bone diameter and marrow diameter (B.Dm and Ma.Dm according to Parfitt et al. [16]) in the cross sections, $11 \mathrm{~mm}$ distal of femoral head in the subtrochanteric region (Fig. 2). We measured at first the B.Dm of the cross sections in a ventro-dorsal direction (in the middle of section) and in a second step on the same line the Ma.Dm. This provides the possibility to avoid many instrumental and operator-dependent errors and it is easy to perform. The B.Dm/Ma.Dm ratio helps us to compare the changes in the cortex of subtrochanteric region of rat femur between all groups.

\section{Serum analysis}

Blood samples (about $5 \mathrm{ml}$ ) were collected from the decapitated animals, allowed to clot, and centrifuged at $3,000 \times \mathrm{g}$ for $10 \mathrm{~min}$. Serum was removed and stored at $-20^{\circ} \mathrm{C}$ until the electrochemiluminescence immunoassay

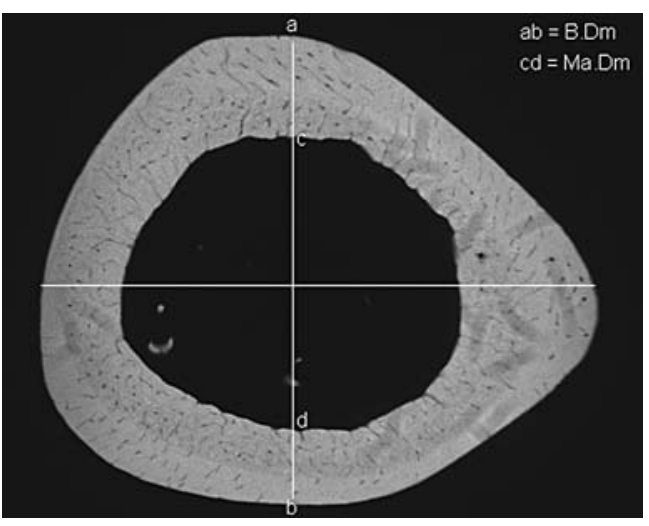

Fig. 2 A radiograph of femoral cross section, $11 \mathrm{~mm}$ distal from femoral head, to measure bone diameter $(\mathrm{B} . \mathrm{Dm}=a b)$ and marrow diameter $(\mathrm{Ma} . \mathrm{Dm}=c d)$. The dorso-ventral line $(a b)$ cuts the horizontal medio-lateral line in the middle of marrow (the histomorphometry software finds this point) and builds a vertical angle $\left(90^{\circ}\right)$. We used the dorso-lateral line for measuring of B.Dm and Ma. $\mathrm{Dm}$ because we could observe on this axis the minimal anatomical norm-variations in subtrochanteric region of rat femur. This region is reliable and easy to evaluate

(ECLIA, Roche diagnostics, Mannheim, Germany) was performed. For an anabolic marker, the level of osteocalcin was analyzed by quantitative determination of the normal minimally inhibitory dose of osteocalcin in the serum. For a marker of bone resorption, the concentration of the Bcrosslaps was quantitatively determined by analyzing the degradation products of type-I collagen in the serum (ECLIA, Roche diagnostics, Mannheim, Germany).

\section{Evaluation and statistics}

The results of the right-left comparison were statistically analyzed in an unconnected pair test (Prism TM, Graph Pad, San Diego, CA, USA). The proportional difference between the strengths of the right and left femurs was determined in each rat, and the average value was calculated. The average value of the proportional differences of the maximum load, failure load, yield load, and the stiffness (elasticity) are signs of the reproducibility and the quality of our new breaking test. In the comparative bioassay, 11 rats per group were evaluated and compared. Differences between the treatment groups were assessed using one-way ANOVA tests (Statistica).

\section{Results}

Comparison of biomechanical parameters of right and left femurs in the new breaking test

In the right-left comparison, the mean difference between the trochanteric loads of the right and left femurs was $9.8 \%$ 
for the maximum load $\left(F_{\max }\right), 11.5 \%$ for the failure load (fL), $21.4 \%$ for the elasticity (stiffness), and 9.3\% for the yield load.

A graphical comparison of the strength of each femur in individual rats showed great similarity. The scatter plots from the results of the right-left comparison are presented in Fig. 3.

Fracture classification

In $26(86.7 \%)$ instances of the breaking test (evaluation test, $n=30$ ), we observed reverse trochanteric fractures of the femurs (type $\mathrm{A}_{3}$ according to AO-classification). A comparison of all of these fractures revealed great similarity not only in the localization but also in the form of the fractures (Fig. 4a-b).

We also observed this fracture type in our comparative bioassay of OVX rats $(n=44)$. In the comparative bioassay (sham, C, E, PTH), we observed in four cases a tilt of the femoral head during the breaking test due to an inaccurate breaking curve. These cases were not taken into consideration. We presented here data only in femurs $(88.6 \%)$ with trochanteric fractures (39 from 44 fractures).
Breaking strength after administration of estradiol or parathyroid hormone

Biomechanical changes in the left femurs were examined after administration of estradiol and parathyroid hormone. The biomechanical parameters $F_{\max }$ and stiffness were significantly higher in the PTH group $\left(F_{\max }=225.3 \mathrm{~N}\right.$, stiffness $=314.9 \mathrm{~N} / \mathrm{mm})$ as compared to the $\mathrm{C}\left(F_{\max }=\right.$ $166 \mathrm{~N}$, stiffness $=235.6 \mathrm{~N} / \mathrm{mm}), \mathrm{E}\left(F_{\max }=182.9 \mathrm{~N}\right.$, stiffness $=237.2 \mathrm{~N} / \mathrm{mm})$, and $\operatorname{sham}\left(F_{\max }=192.10 \mathrm{~N}\right.$, stiffness $=$ $267.0 \mathrm{~N} / \mathrm{mm}$ ) groups. In the $\mathrm{E}$ group, the mean values of the biomechanical parameters were higher than those of the $\mathrm{C}$ group, but these differences were not significant. The mean value of the yield load was in the PTH group higher as compared to the $\mathrm{E}$ and $\mathrm{C}$ and sham group, but these changes were statistically not significant (Table 1).

Histomorphometric changes in the proximal femur after administration of estradiol and parathyroid hormone

The results of the histomorphometric analysis and microarchitectural parameters are summarized in Table 1.

The results of $\mathrm{Tb} . \mathrm{Ar}, \mathrm{N} . \mathrm{Nd} / \mathrm{mm}^{2}$, and $\mathrm{Tb} . \mathrm{Wi}$ were significantly higher in the PTH group (Tb.Ar=75.65\%, N.
Fig. 3 Scatter plots from rightleft comparison of rat femurs in the new breaking test. The mean difference between the trochanteric loads of both femurs $9.8 \%$ for the maximum load $\left(F_{\max }\right)$, $11.5 \%$ for the failure load (fL), $21.4 \%$ for the stiffness (elasticity), and $9.3 \%$ for the yield load

\section{Right - Left - Comparison} Femora
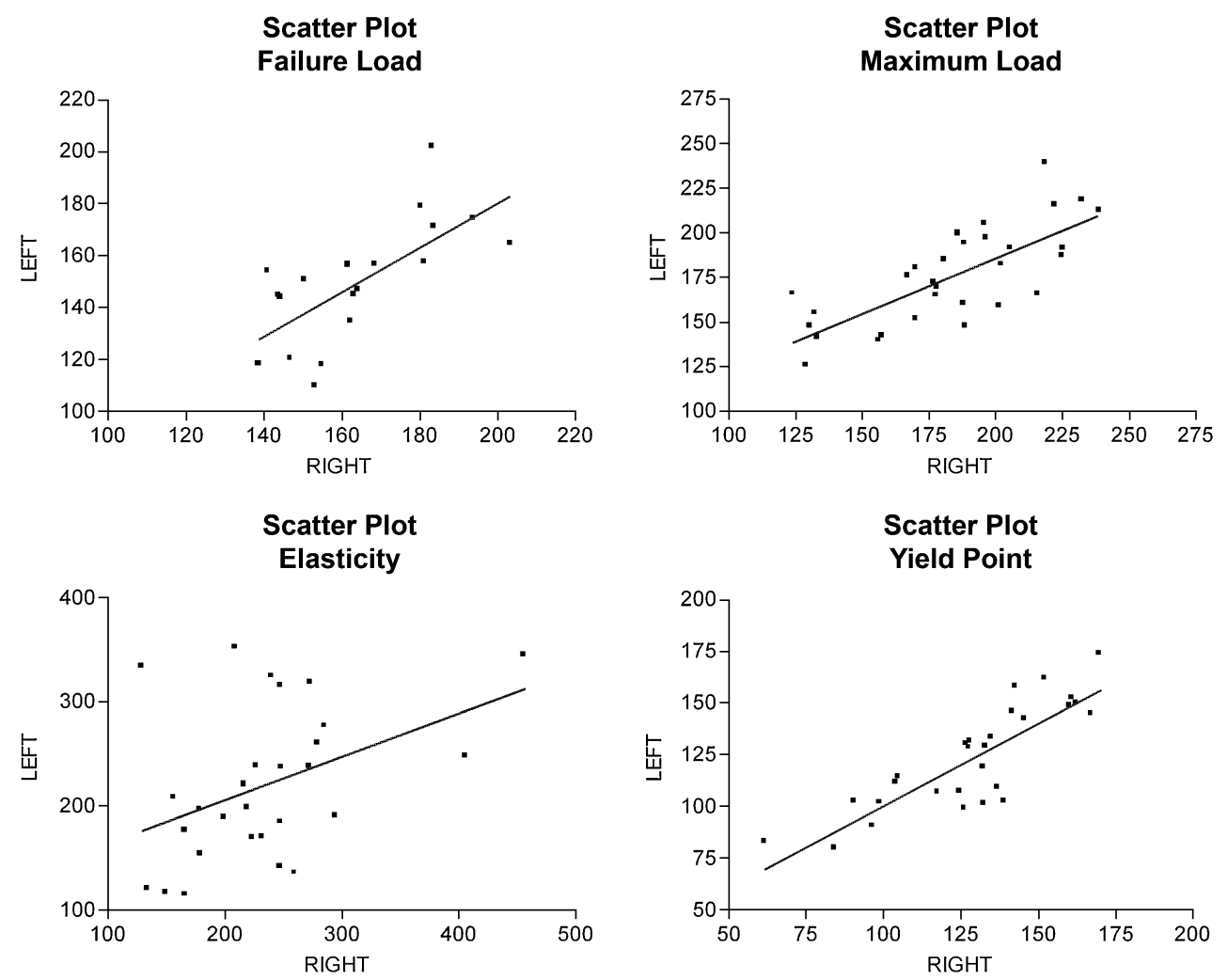


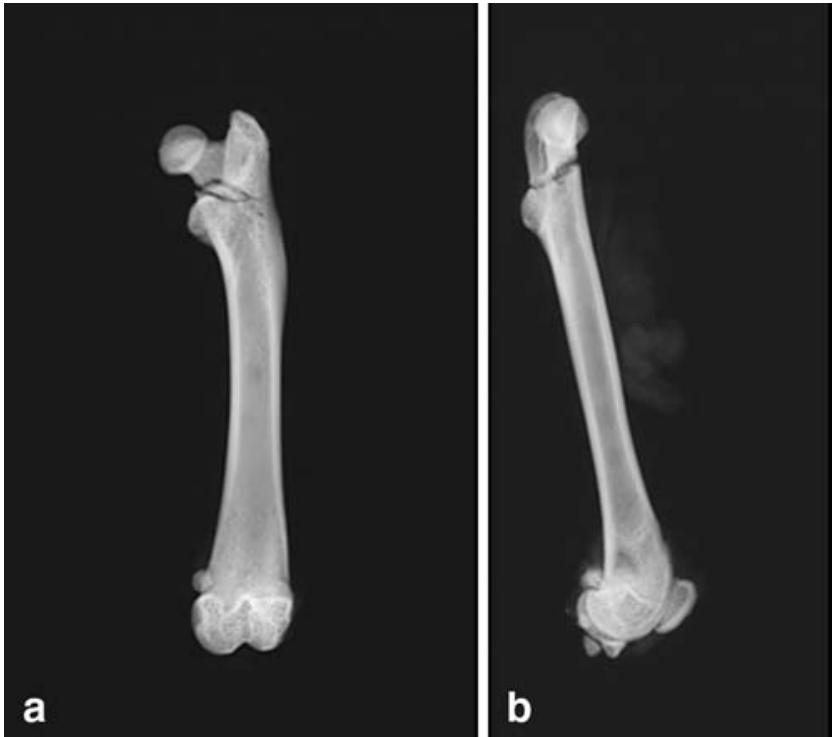

Fig. 4 Radiographs of proximal rat femur after breaking test. We observed in $86.6 \%$ of cases (in right-left comparison) a reverse trochanteric fracture (type $\mathrm{A}_{3}$ according to $\mathrm{AO}$ classification; a anterior-posterior view, b lateral view)

$\left.\mathrm{Nd} / \mathrm{mm}^{2}=41.32, \mathrm{~Tb} . \mathrm{Wi}=9.80 \mu \mathrm{m}\right)$ in comparison to the $\mathrm{C}$ group (Tb.Ar $=57.18 \%, \mathrm{~N} . \mathrm{Nd} / \mathrm{mm}^{2}=34.35, \mathrm{~Tb} . \mathrm{Wi}=$ $7.62 \mu \mathrm{m})$. We found a significantly higher value for the PTH compared to E groups concerning the Tb.Ar. Although the mean values of Tb.Ar, N.Nd/mm ${ }^{2}$, and $\mathrm{Tb} . \mathrm{Wi}$ were higher in the E-treated rats $\left(\mathrm{Tb} . \mathrm{Ar}=61.04 \%, \mathrm{~N} . \mathrm{Nd} / \mathrm{mm}^{2}=\right.$ 40.66, $\mathrm{Tb} . \mathrm{Wi}=7.53$ ) than in the $\mathrm{C}$, these differences were statistically not significant. The Tb.Wi in the PTH rats was significantly higher compared to the sham animals $(\mathrm{Tb} . \mathrm{Wi}=$ $8.5 \mu \mathrm{m}$; Fig. 5).

The mean of B.Dm/Ma.Dm ratio was in the PTH group (1.938) significantly higher than $\mathrm{C}$ group (1.716). The reason for this was mainly due to greater Ma.Dm in the $\mathrm{C}$ animals. The E (1.749) and sham (1.740) rats showed a higher B.Dm/Ma.Dm ratio than $\mathrm{C}$ but the results were not statistically significant (Table 1).

\section{Serum analysis}

Serum osteocalcin levels differed between the groups $(p<$ $0.05)$. The highest level of osteocalcin was observed in the PTH-treated group $(45.46 \mathrm{ng} / \mathrm{ml})$, followed by the osteoporotic $\mathrm{C}$ group $(17.78 \mathrm{ng} / \mathrm{ml})$. In E-treated rats $(5.35 \mathrm{ng} /$ $\mathrm{ml}$ ), osteocalcin levels were lower than PTH. The concentration of the $\beta$-crosslaps in E- $(46.86 \mathrm{ng} / \mathrm{ml})$ and PTHtreated $(45.66 \mathrm{ng} / \mathrm{ml})$ animals were slightly, but not significantly, enhanced compared to the $\mathrm{C}$ group (33.83 ng/ml; Table 1). The sham animals showed the lowest level of $\beta$-crosslaps $(4.04 \mathrm{ng} / \mathrm{ml})$ and osteocalcin (2 $\mathrm{ng} / \mathrm{ml})$.

Table 1 The results from comparative bioassay: body weight, biomechanical test, histomorphometry, and serum analysis

\begin{tabular}{|c|c|c|c|c|c|c|c|c|}
\hline & \multicolumn{2}{|l|}{ Sham } & \multicolumn{2}{|l|}{ OVX } & \multicolumn{2}{|c|}{ Estradiol benzoate } & \multicolumn{2}{|c|}{ Parathyroid hormone } \\
\hline & Mean & STD & Mean & STD & Mean & STD & Mean & STD \\
\hline Body weight (g) & $275.6^{\mathrm{a}}$ & 14.31 & 342.2 & 19.91 & $280.3^{\mathrm{a}}$ & 12.05 & $324.9^{\mathrm{b}, \mathrm{c}}$ & 19.38 \\
\hline \multicolumn{9}{|l|}{ Serum analysis } \\
\hline Osteocalcin (ng/ml) & $2^{\mathrm{a}}$ & 2.0 & 17.78 & 5.64 & $5.347^{\mathrm{a}}$ & 1.79 & $45.46^{\mathrm{a}, \mathrm{b}, \mathrm{c}}$ & 5.22 \\
\hline Crosslaps (ng/ml) & $4.04^{\mathrm{a}}$ & 0.25 & 33.83 & 8.37 & 46.86 & 34.25 & $45.66^{\mathrm{b}}$ & 19.56 \\
\hline \multicolumn{9}{|l|}{ Biomechanical test } \\
\hline Maximum load (N) & $192.1^{\mathrm{a}}$ & 20.49 & 166.03 & 38.36 & $182.92^{b}$ & 13.83 & $225.25^{\mathrm{a}, \mathrm{b}, \mathrm{c}}$ & 46.55 \\
\hline Yield load (N) & 120.2 & 16.48 & 111.57 & 31.33 & 113.14 & 10.04 & 132.00 & 18.69 \\
\hline Stiffness (N/mm) & $267.0^{\mathrm{a}}$ & 26.10 & 235.56 & 40.82 & $237.15^{\mathrm{b}}$ & 45.40 & $314.87^{\mathrm{a}, \mathrm{b}, \mathrm{c}}$ & 72.05 \\
\hline \multicolumn{9}{|l|}{ Histomorphometry } \\
\hline $\mathrm{N} . \mathrm{Nd} / \mathrm{mm}^{2}$ & $48.54^{\mathrm{a}}$ & 5.439 & 34.35 & 6.97 & $40.66^{\mathrm{b}}$ & 6.24 & $41.32^{\mathrm{a}}$ & 4.36 \\
\hline Tb.Ar (\%) & $77.25^{\mathrm{a}}$ & 10.73 & 57.18 & 13.62 & $61.04^{\mathrm{b}}$ & 8.27 & $75.65^{\mathrm{ac}}$ & 9.02 \\
\hline Tb.Wi (mcm) & $8.5^{\mathrm{a}}$ & 1.38 & 7.62 & 0.95 & $7.53^{\mathrm{b}}$ & 1.25 & $9.80^{\mathrm{abc}}$ & 1.27 \\
\hline B.Dm (mcm) & 3,154 & 135.9 & 3,137 & 280.6 & 3,140 & 161.1 & 3,151 & 124.1 \\
\hline Ma.Dm (mcm) & 1,814 & 67.78 & 1,838 & 221.4 & 1,792 & 123.4 & $1,615^{\mathrm{a}, \mathrm{b}, \mathrm{c}}$ & 132.5 \\
\hline B.Dm/Ma.Dm & 1.740 & 0.063 & 1.716 & 0.08 & 1.749 & 0.069 & $1.938^{\mathrm{a}, \mathrm{b}, \mathrm{c}}$ & 0.069 \\
\hline
\end{tabular}

Tb. Ar ratio of trabecular area, $N . N d / m^{2}$ connectivity, Tb. Wi trabecular thickness, B.Dm bone diameter, Ma.Dm marrow diameter

${ }^{\mathrm{a}} \mathrm{Sham} / \mathrm{E} / \mathrm{PTH}$ vs. OVX $(p<0.05)$

${ }^{\mathrm{b}} \mathrm{E} / \mathrm{PTH}$ vs. sham $(p<0.05)$

${ }^{\mathrm{c}}$ PTH vs. E $(p<0.05)$ 

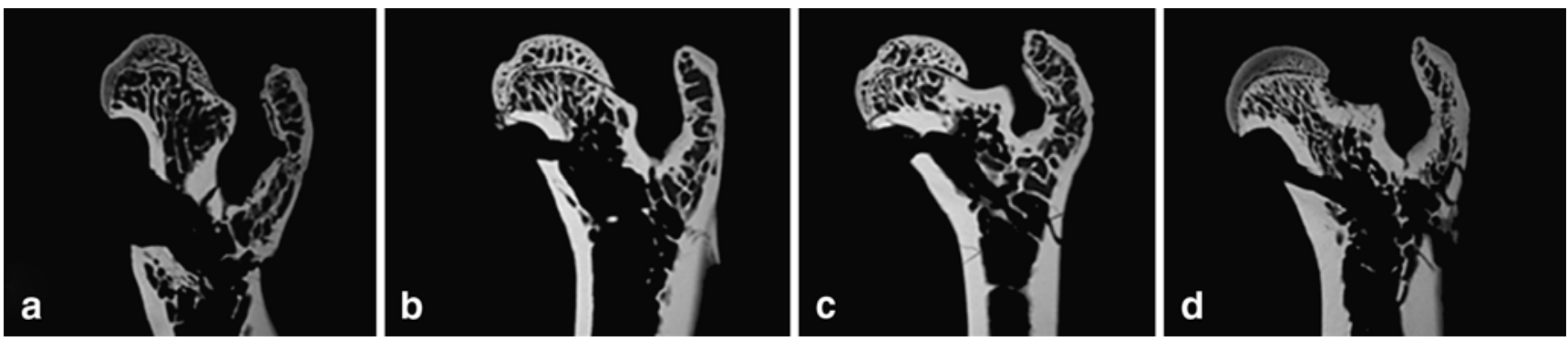

Fig. 5 Microradiographs of the proximal femur of rat show the high content of both cortical and trabecular surfaces (after breaking test). a The control group (C) with a low trabecular density. b The rat femur

after treatment with estradiol, c the sham group, and $\mathbf{d}$ after substitution with PTH (high trabecular content and thick cortical shell)

Results of intravital fluorochrome labeling of cortical bone of proximal rat femur

Using the digital imaging system, it was possible to outline the regions labeled by the fluorescent agents. Because of low color intensity of xylenol orange bands (XO) and its overlabeling by $\mathrm{CG}$, we measured the different mineralization times mainly marked by the red (AK), light green (CG and Xo), and yellow (TC) labels (Table 2). The PTH group demonstrated the highest bone remodeling and restoration activities on both periosteal $(34.6 \mathrm{mcm})$ and especially endosteal (47 $\mathrm{mcm}$ and significantly higher than other groups) surfaces. In contrast, in the E-treated animals, only a minimal enhancement of bone remodeling of the periosteal $(5.2 \mathrm{mcm})$ and endosteal $(6.9 \mathrm{mcm})$ side was observed. In the $\mathrm{C}$ group, the periosteal remodeling $(21.8 \mathrm{mcm})$ seems to be less dramatic than in the PTH group but the differences were statistically not significant (Fig. 6). In the $\mathrm{C}$ rats, we did not observe any endosteal appositions. The sham animals showed significantly lower appositions in the periosteal $(13.3 \mathrm{mcm})$ and endosteal $(14.7 \mathrm{mcm})$ side of the cortex in comparison to the PTH group.

\section{Discussion}

Trochanteric fracture in the novel breaking test

The trochanteric fracture of the human femur is one of the most frequent fracture types of osteoporotic skeleton. The trochanteric region of the rat femur shows great similarity with the trochanteric area of the human femur. Because there are many similarities between human and rat bone at the cellular and tissue levels (trabecular bone, endocortical envelope), the use of the rat proximal femur is as good as any other routinely used non-human skeletal site for assessing bone mor-

phometric changes [17]. The proximal (medial) part of the femoral neck in rats and other large animals seems to not be covered by periosteal tissue. This is an important factor to consider, especially when anabolic agents are tested with pronounced periosteal stimulation [18]. In contrast, the trochanteric region contains a cortical surface covered by a sufficient periosteum. Furthermore, the trochanteric region has a high content of trabecular net.

The clear advantage of using the proximal femur is the opportunity it provides to measure both cortical and trabecular bone histomorphometric parameters as well as mechanical properties of the bone within the same skeletal area [19]. Biomechanical tests of this part of skeleton in osteoporosis studies seem to be valuable and reliable.

The most conventional methods for evaluating rat hip failure force are based on the axial compression approach [14]. However, as most osteoporotic hip fractures result from lateral falls, it seems logical and necessary to establish mechanical testing methods closer to clinical conditions.

In our study, the reproducibility of the biomechanical test of the rat femurs was determined by comparing the data from the right and left femurs of the non-OVX rats. Our new breaking test yielded no significant systematic differences concerning the mechanical characteristics of the right and left femurs. Side comparative studies in human and animals show intraindividual variations of the same dimension that are found in our right-left comparison. In humans, we know there are differences (up to 15\%) in size and strength of the right and left lower extremity (anklebone) or upper extremity (right- or left-handed person) [15]. The analysis of the fracture type producing in our breaking test showed in the right-left-comparison test in $86.6 \%$ and in the biocomparative assay in $88.6 \%$ of the animals a reversed trochanteric fracture of femur (type $\mathrm{A}_{3}$ according to the AO classification). These results demonstrate the high reproducibility of our new mechanical testing method. 
Table 2 The results from intravital fluorochrome labeling

\begin{tabular}{|c|c|c|c|c|c|c|c|c|}
\hline & \multicolumn{2}{|l|}{ Sham } & \multicolumn{2}{|l|}{ OVX } & \multicolumn{2}{|c|}{ Estradiol benzoate } & \multicolumn{2}{|c|}{ Parathyroid hormone } \\
\hline & Mean & STD & Mean & STD & Mean & STD & Mean & STD \\
\hline \multicolumn{9}{|l|}{ Periosteal apposition } \\
\hline \multicolumn{9}{|c|}{ Absolute apposition band width (mcm) } \\
\hline Calcein green (days $0-18$ ) & $3.6^{\mathrm{a}}$ & 1.4 & 9.4 & 4.4 & $1.5^{\mathrm{a}, \mathrm{b}}$ & 0.7 & $11.6^{\mathrm{b}, \mathrm{c}}$ & 8.7 \\
\hline Alizarin red (days 18-24) & 5.2 & 1.3 & 6.4 & 3.7 & $2.3^{\mathrm{a}, \mathrm{b}}$ & 1.4 & $10.4^{\mathrm{b}, \mathrm{c}}$ & 7.9 \\
\hline Tetracycline (days 24-35) & 4.5 & 2.0 & 6.0 & 3.2 & $1.4^{\mathrm{a}, \mathrm{b}}$ & 0.8 & $12.6^{\mathrm{b}, \mathrm{c}}$ & 8.9 \\
\hline Sum & $13.3^{\mathrm{a}}$ & & 21.8 & & $5.2^{\mathrm{a}, \mathrm{b}}$ & & $34.6^{\mathrm{b}, \mathrm{c}}$ & \\
\hline \multicolumn{9}{|c|}{ Absolute apposition band width per day ( $\mathrm{mcm})$} \\
\hline Calcein green & $0.2^{\mathrm{a}}$ & 0.1 & 0.5 & 0.2 & $0.08^{\mathrm{a}, \mathrm{b}}$ & 0.04 & $0.6^{\mathrm{b}, \mathrm{c}}$ & 0.5 \\
\hline Alizarin red & 0.9 & 0.2 & 1.1 & 0.6 & $0.4^{\mathrm{a}, \mathrm{b}}$ & 0.2 & $1.7^{\mathrm{b}, \mathrm{c}}$ & 1.3 \\
\hline Tetracycline & 0.4 & 0.2 & 0.5 & 0.3 & $0.1^{\mathrm{a}, \mathrm{b}}$ & 0.07 & $1.1^{\mathrm{b}, \mathrm{c}}$ & 0.8 \\
\hline Sum & $1.5^{\mathrm{a}}$ & & 2.1 & & $0.6^{\mathrm{a}, \mathrm{b}}$ & & $3.4^{\mathrm{b}, \mathrm{c}}$ & \\
\hline \multicolumn{9}{|c|}{ Endosteal apposition } \\
\hline \multicolumn{9}{|c|}{ Absolute apposition band width (mcm) } \\
\hline Calcein green (days $0-18$ ) & $2.0^{\mathrm{a}}$ & 1.4 & \multirow{4}{*}{\multicolumn{2}{|c|}{ No significant appositions }} & $2.3^{\mathrm{a}}$ & 1.2 & $17.8^{\mathrm{a}, \mathrm{b}, \mathrm{c}}$ & 3.5 \\
\hline Alizarin red (days 18-24) & $2.7^{\mathrm{a}}$ & 2.3 & & & $3.2^{\mathrm{a}}$ & 1.7 & $14.0^{\mathrm{a}, \mathrm{b}, \mathrm{c}}$ & 3.5 \\
\hline Tetracycline (days 24-35) & 0 & 0 & & & $1.4^{\mathrm{a}}$ & 0.7 & $15.6^{\mathrm{a}, \mathrm{b}, \mathrm{c}}$ & 4.6 \\
\hline Sum & $4.7^{\mathrm{a}}$ & & & & $6.9^{\mathrm{a}}$ & & $47^{\mathrm{a}, \mathrm{b}, \mathrm{c}}$ & \\
\hline \multicolumn{9}{|c|}{ Absolute apposition band width per day (mcm) } \\
\hline Calcein green & $0.1^{\mathrm{a}}$ & 0.1 & \multirow{4}{*}{\multicolumn{2}{|c|}{ No significant appositions }} & $0.1^{\mathrm{a}}$ & 0.06 & $1.0^{\mathrm{a}, \mathrm{b}, \mathrm{c}}$ & 0.2 \\
\hline Alizarin red & $0.5^{\mathrm{a}}$ & 0.4 & & & $0.5^{\mathrm{a}}$ & 0.3 & $2.3^{\mathrm{a}, \mathrm{b}, \mathrm{c}}$ & 0.6 \\
\hline Tetracycline & 0 & 0 & & & $0.1^{\mathrm{a}}$ & 0.06 & $1.4^{\mathrm{a}, \mathrm{b}, \mathrm{c}}$ & 0.4 \\
\hline Sum & $0.6^{\mathrm{a}}$ & & & & $0.7^{\mathrm{a}}$ & & $4.7^{\mathrm{a}, \mathrm{b}, \mathrm{c}}$ & \\
\hline
\end{tabular}

The widths of apposition bands, calcein green, alizarin red, and tetracycline in cortical surface in subtrochanteric cross sections of rat femurs (11 mm distal from femoral head) were measured by fluorescence microscopy $(\times 400)$

${ }^{\mathrm{a}} \mathrm{Sham} / \mathrm{E} / \mathrm{PTH}$ vs. OVX $(p<0.05)$

${ }^{\mathrm{b}} \mathrm{E} / \mathrm{PTH}$ vs. sham $(p<0.05)$

${ }^{\mathrm{c}}$ PTH vs. E $(p<0.05)$

Biomechanical strength after administration of estrogen and parathyroid hormone

The antiosteoporotic effect of estrogen in OVX rats has been shown in many recent studies $[15,20,21]$. This effect has been confirmed not only by biomechanical tests but also in histomorphometric analyses of different skeletal sites, including the proximal tibia and lumbar vertebra.

It is known that hormone replacement therapy with estrogen produces the best therapeutic effects in osteoporosis that arises as a consequence of estrogen deficiency, such as post-menopausal or ovariectomized conditions. The antiosteoporotic effect of estrogen substitution is mainly seen after an early substitution of this hormone.

While in the present study the mean values were clearly higher in the $\mathrm{E}$ group in comparison to $\mathrm{C}$ rats, there were no significant differences in the biomechanical tests between the $\mathrm{E}$ and $\mathrm{C}$ groups. The possible reasons for this may be the small number of animals, the short treatment period, and the late therapy beginning with $\mathrm{E}$ (significant bone loss has already occurred 8 weeks after OVX before E substitution).

The analysis of the results from the breaking tests showed significant differences between PTH-treated vs. sham and E-treated rats concerning stiffness and $F_{\max }$. The known latency of $\mathrm{E}$ treatment in contrast to the pronounced early anabolic effects of PTH on trabecular bone density seems, in addition to the significantly higher endosteal bone remodeling, to be the main reasons for the higher femoral strength in the PTH group in comparison to both the Etreated and the sham animals.

Histomorphometric changes after administration of estrogen and parathyroid hormone

After estrogen treatment, we did not observed any significant increases of the $\mathrm{Tb} . \mathrm{Ar}, \mathrm{N} . \mathrm{Nd} / \mathrm{mm}^{2}$ of proximal 


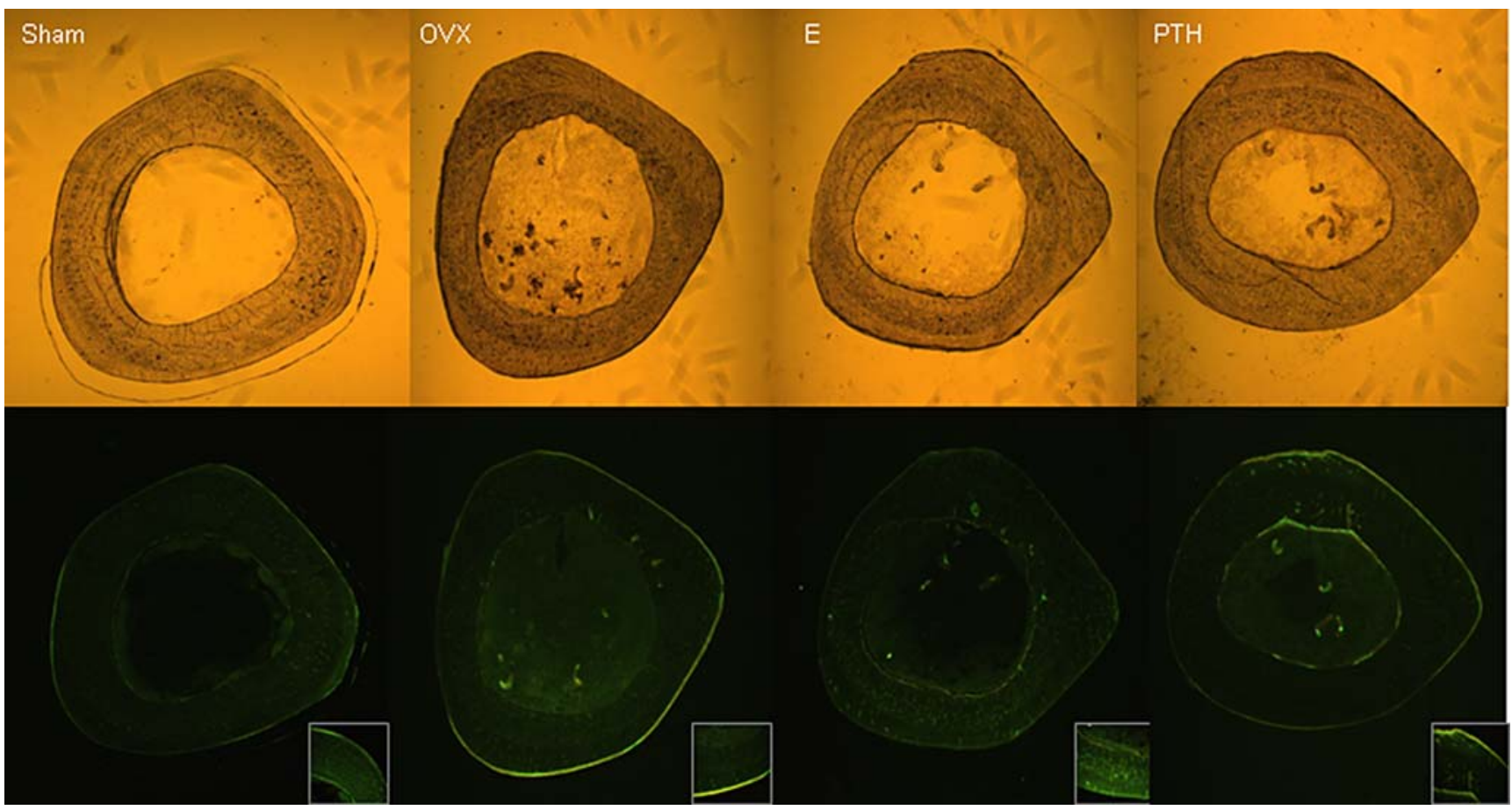

Fig. 6 Transversal sections from the proximal femur (all sections $11 \mathrm{~mm}$ distal from femoral head, subtrochanteric region) of OVX rats treated with PTH and E for 5 weeks and sham group. The sections were studied by fluorescence microscopy. In the sham group, only a minimal periosteal and endosteal bone formation could be observed. In the OVX group, there was no endosteal but a clear periosteal

femur. In contrast, the PTH treatment induced a significant increase of trabecular bone area and connectivity compared to the $\mathrm{C}$ group. Although the B.Dm did not show any significant changes between the groups, the results of the B.Dm/Ma.Dm ratio demonstrated a significantly better outcome in the PTH animals. As there were not any significant changes concerning B.Dm, measured in the subtrochanteric region of all femurs, the better B.Dm/Ma. Dm ratios in the PTH rats seemed to be mainly caused by an increase in endosteal bone formation of cortex. This causes significantly lesser Ma.Dm in the PTH animals. The cortical changes that are normally difficult to evaluate could be reliably shown with the B.Dm/Ma.Dm ratio. These results, in addition to the results of fluorescence microscopy, provide useful information about intensity and localization (endosteal and/or periosteal) of bone remodeling (apposition) and drug influences within the cortical area. The increased bone formation rate was observed under PTH treatment both at the periosteal and endosteal side by fluorescent-microscopic analysis of the cross sections from the proximal femur. The endosteum here seems to be one of the targets of PTH with an accelerate bone formation and a pronounced filling in of intracortical cavities [8, 22]. activity. The E-treated animals showed very weak periosteal and endosteal appositions. In contrast, PTH seems to induce both endosteal and periosteal bone formation. Please note the changes between the groups concerning bone geometry and the width of bone marrow (Ma.Dm) in the upper pictures

The significantly higher serum level of osteocalcin in the PTH group confirms the strong anabolic effect of this antiosteoporotic agent.

Although the estrogen is known to increase bone mass and strength by a suppression of bone resorption, in our study, the biomechanical and histomorphometric results of $\mathrm{E}$ were not significantly better than $\mathrm{C}$ group. We have to point out here that in our study design, 8 weeks after OVX, a significant trabecular bone loss has already occurred. The E substitution presented in our study was not able to suppress the B-crosslap level in serum. In our opinion, the large standard deviation concerning $\beta$-crosslap level in the $E$ rats makes an adequate interpretation of these results difficult. However, the possible reasons for the weak antiosteoporotic effect of $\mathrm{E}$ in our work may be the dose, length, and especially the late beginning of $E$ therapy. It is also important to mention that the intensity of antiosteoporotic effect of E and PTH seems, like that of many other antiresorptive and anabolic drugs, can vary (stronger or weaker) on different skeletal sites (vertebral body, tibia,...) or in different species (rat, human, etc.).

According to our data, the higher endosteal bone formation and the improvement of trabecular morphometry 
seem to be responsible for the better biomechanical results in the PTH-treated rats in comparison to $\mathrm{E}$ and sham group.

Our results provide a structural basis for the recent demonstrations that PTH treatment seems to reduce the incidence of osteoporosis-related fractures [23, 24], though further experiments are needed to determine whether PTH is also able to prevent trochanteric fractures. It is important to mention here that all of these effects and differences depend not only on the dose but also on the length of treatment with $\mathrm{E}$ or PTH. It is thus necessary to conduct dose- and time-related investigations in a second line of inquiry.

In conclusion, we have introduced and validated a novel method to produce trochanteric fracture for assessing the strength of the trochanteric region of the rat femur. Our findings indicate that PTH treatment increases bone formation mainly on the endosteal and minimally periosteal side of cortical area of the proximal femur in OVX rat and also improves the trabecular micro-architecture. Our results show that the trochanteric region of the rat femur (next to the other skeletal sites) must also be mentioned as a further skeletal location for studies of the antiosteoporotic effects of drugs, as it contains both trabecular and cortical bone with an intact periosteal shell.

Acknowledgments The authors thank F. Kauer, R. Castro, and A. Witt for their support of the animal trial. The authors thank also the AO foundation for their support.

\section{Conflicts of interest None.}

Open Access This article is distributed under the terms of the Creative Commons Attribution Noncommercial License which permits any noncommercial use, distribution, and reproduction in any medium, provided the original author(s) and source are credited.

\section{References}

1. Sliwinski L, Folwarczna J, Janiec W, Grynkiewicz G, Kuzyk K (2005) Differential effects of genistein, estradiol and raloxifene on rat osteoclasts in vitro. Pharmacol Rep 57:352-359

2. Burger H (2003) Hormone replacement therapy in the postWomen's Health Initiative era. Report of a meeting held in Funchal, Madeira, February 24-25, 2003. Climacteric 6(Suppl 1):11-36

3. Wuttke W, Jarry H, Westphalen S, Christoffel V, Seidlova-Wuttke D (2002) Phytoestrogens for hormone replacement therapy? J Steroid Biochem Mol Biol 83:133-147

4. Eriksen EF (2002) Primary hyperparathyroidism: lessons from bone histomorphometry. J Bone Miner Res 17(Suppl 2):N95N97

5. Matsumoto $T$, Shiraki $M$, Hagino $H$, Iinuma $H$, Nakamura $T$ (2006) Daily nasal spray of hPTH(1-34) for 3 months increases bone mass in osteoporotic subjects: a pilot study. Osteoporos Int 17:1532-1538

6. Gonnelli S, Martini G, Caffarelli C, Salvadori S, Cadirni A, Montagnani A, Nuti R (2006) Teriparatide's effects on quantitative ultrasound parameters and bone density in women with established osteoporosis. Osteoporos Int 17:1524-1531

7. Partridge NC, Li X, Qin L (2006) Understanding parathyroid hormone action. Ann N Y Acad Sci 1068:187-193

8. Ejersted C, Andreassen TT, Nilsson MH, Oxlund H (1994) Human parathyroid hormone(1-34) increases bone formation and strength of cortical bone in aged rats. Eur J Endocrinol 130:201-207

9. Neer RM, Arnaud CD, Zanchetta JR, Prince R, Gaich GA, Reginster JY, Hodsman AB, Eriksen EF, Ish-Shalom S, Genant HK, Wang O, Mitlak BH (2001) Effect of parathyroid hormone (1-34) on fractures and bone mineral density in postmenopausal women with osteoporosis. N Engl J Med 344:1434-1441

10. Deal C, Omizo M, Schwartz EN, Eriksen EF, Cantor P, Wang J, Glass EV, Myers SL, Krege JH (2005) Combination teriparatide and raloxifene therapy for postmenopausal osteoporosis: results from a 6-month double-blind placebo-controlled trial. J Bone Miner Res 20:1905-1911

11. Ishihara A, Sasaki T, Debari K, Furuya R, Kawawa T, Ramamurthy NS, Golub LM (1999) Effects of ovariectomy on bone morphology in maxillae of mature rats. J Electron Microsc (Tokyo) 48:465-469

12. Thompson DD, Simmons HA, Pirie CM, Ke HZ (1995) FDA Guidelines and animal models for osteoporosis. Bone 17:125S$133 \mathrm{~S}$

13. Wronski TJ, Lowry PL, Walsh CC, Ignaszewski LA (1985) Skeletal alterations in ovariectomized rats. Calcif Tissue Int 37:324-328

14. Zhang G, Qin L, Shi Y, Leung K (2005) A comparative study between axial compression and lateral fall configuration tested in a rat proximal femur model. Clin Biomech (Bristol, Avon) 20:729-735

15. Sturmer EK, Seidlova-Wuttke D, Sehmisch S, Rack T, Wille J, Frosch KH, Wuttke W, Sturmer KM (2006) Standardized bending and breaking test for the normal and osteoporotic metaphyseal tibias of the rat: effect of estradiol, testosterone, and raloxifene. J Bone Miner Res 21:89-96

16. Parfitt AM, Drezner MK, Glorieux FH, Kanis JA, Malluche H, Meunier PJ, Ott SM, Recker RR (1987) Bone histomorphometry: standardization of nomenclature, symbols, and units. Report of the ASBMR Histomorphometry Nomenclature Committee. J Bone Miner Res 2:595-610

17. Bagi CM, Wilkie D, Georgelos K, Williams D, Bertolini D (1997) Morphological and structural characteristics of the proximal femur in human and rat. Bone 21:261-267

18. Mosekilde L, Danielsen CC, Gasser J (1994) The effect on vertebral bone mass and strength of long term treatment with antiresorptive agents (estrogen and calcitonin), human parathyroid hormone-(1-38), and combination therapy, assessed in aged ovariectomized rats. Endocrinology 134:2126-2134

19. Bagi CM, Ammann P, Rizzoli R, Miller SC (1997) Effect of estrogen deficiency on cancellous and cortical bone structure and strength of the femoral neck in rats. Calcif Tissue Int 61:336-344

20. Mukherjee M, Das AS, Das D, Mukherjee S, Mitra S, Mitra C (2006) Effects of garlic oil on postmenopausal osteoporosis using ovariectomized rats: comparison with the effects of lovastatin and 17beta-estradiol. Phytother Res 20:21-27

21. Shen V, Birchman R, Xu R, Otter M, Wu D, Lindsay R, Dempster DW (1995) Effects of reciprocal treatment with estrogen and 
estrogen plus parathyroid hormone on bone structure and strength in ovariectomized rats. J Clin Invest 96:2331-2338

22. Oxlund H, Ortoft G, Thomsen JS, Danielsen CC, Ejersted C, Andreassen TT (2006) The anabolic effect of PTH on bone is attenuated by simultaneous glucocorticoid treatment. Bone 39:244-252

23. Vestergaard P, Jorgensen NR, Mosekilde L, Schwarz P (2007) Effects of parathyroid hormone alone or in combination with antiresorptive therapy on bone mineral density and fracture riska meta-analysis. Osteoporos Int 18:45-57

24. Dempster DW, Cosman F, Kurland ES, Zhou H, Nieves J, Woelfert L, Shane E, Plavetic K, Muller R, Bilezikian J, Lindsay R (2001) Effects of daily treatment with parathyroid hormone on bone microarchitecture and turnover in patients with osteoporosis: a paired biopsy study. J Bone Miner Res $16: 1846-1853$ 